\title{
Posttraumatic osteoarthritis: pathogenesis and pharmacological treatment options
}

\author{
Martin K Lotz*
}

\begin{abstract}
Joint trauma can lead to a spectrum of acute lesions, including osteochondral fractures, ligament or meniscus tears and damage to the articular cartilage. This is often associated with intraarticular bleeding and causes posttraumatic joint inflammation. Although the acute symptoms resolve and some of the lesions can be surgically repaired, joint injury triggers a chronic remodeling process in cartilage and other joint tissues that ultimately manifests as osteoarthritis in a majority of cases. The objective of the present review is to summarize information on pathogenetic mechanisms involved in the acute and chronic consequences of joint trauma and discuss potential pharmacological interventions. The focus of the review is on the early events that follow joint trauma since therapies for posttraumatic joint inflammation are not available and this represents a unique window of opportunity to limit chronic consequences.
\end{abstract}

\section{Introduction}

Joint trauma leads to acute posttraumatic arthritis and in the majority of individuals, as a long-term complication, to osteoarthritis (OA) [1]. There are an estimated 900,000 cases of knee injuries annually in the United States, and posttraumatic OA accounts for $12 \%$ of all cases of OA [2]. In some joints, such as the ankle, OA predominantly develops after joint trauma [2]. As posttraumatic OA primarily affects younger individuals [3,4], it leads to reduced physical activity and to deconditioning of the musculoskeletal system. Joint replacement in this young patient group is complicated by the limited lifespan of the implants.

OA risk increases with patient age at the time of injury and with time from the onset of injury $[4,5]$. The presence

*Correspondence: mlotz@scripps.edu

Department of Molecular and Experimental Medicine, The Scripps Research Institute, 10550 North Torrey Pines Road, La Jolla, CA 92037, USA of additional OA risk factors, such as obesity, joint malalignment or genetic risk factors, leads to a more severe outcome. Between 60 and $80 \%$ of patients with magnetic resonance imaging or arthroscopically documented cartilage injury developed cartilage degeneration within 5 years [6,7]. Patients with anterior cruciate ligament (ACL)-deficient knees, with or without a concomitant meniscus injury, are at high risk for posttraumatic OA $[5,8]$. Previous concepts that residual joint instability after ACL reconstruction is the cause of OA have not been confirmed as OA develops in joints with ACL injuries even if reconstructive surgery successfully normalizes joint biomechanics. These observations emphasize the role of events in the time period after the initial joint trauma.

Joint trauma affects all joint tissues to some degree but the damage to articular cartilage appears most significant, as it is largely irreversible and may be the major determinant for the subsequent development of OA. There is a certain degree of immediate or irreversible damage, but the days and weeks after injury represent the phase where damage progresses most rapidly. The acute symptoms following joint injury include joint pain and swelling due to intraarticular bleeding, synovial effusion and inflammatory cell infiltration. Patients typically undergo surgical treatment of the ligament and meniscus lesions within 3 months after the initial injury [2]. Currently there are no approved therapies to address acute posttraumatic arthritis. Corticosteroids have potent anti-inflammatory activity but potential benefits or adverse effects of corticosteroids in a restricted dose and frequency of administration for traumatic joint injury have not been resolved and remain to be studied.

Furthermore, measures to prevent OA are not available, although patients with posttraumatic arthritis represent a readily identified population at risk for developing OA and thus are ideal to test preventive and therapeutic measures. Interventions early during the most dynamic postinjury phase have the potential to limit the degree of acute joint damage and to delay the onset and reduce the severity of OA. The prolonged posttraumatic inflammatory insult also significantly increases the risk of arthrofibrosis for which satisfactory management remains to be developed. The present review addresses pathogenetic 
Table 1. Pathogenesis of posttraumatic cartilage degradation

\begin{tabular}{lll}
\hline Immediate (seconds) & Acute (months) & Chronic (years) \\
\hline Cell necrosis & Apoptosis & Joint tissue remodeling \\
Collagen rupture & Leukocyte infiltration & \\
Glycosaminoglycan loss & Inflammatory mediators & \\
Hemarthrosis & Extracellular matrix degradation & \\
& Deficient lubricants & \\
& Arthrofibrosis & \\
\hline
\end{tabular}

mechanisms and mediators involved in the acute and chronic consequences of joint trauma and candidates for pharmacological intervention.

\section{Pathogenetic mechanisms}

The pathogenetic processes can temporally be separated into the immediate events that are related to the mechanical impact, the acute posttraumatic phase with prominent inflammation that can last up to approximately 2 months and the chronic phase. Subtle metabolic changes in cartilage and other joint structures slowly progress through a long clinically asymptomatic latency period to a symptomatic phase with joint pain and dysfunction. In the majority of patients this leads to a clinical diagnosis of $\mathrm{OA}$, and in some patients ultimately requires joint replacement (Table 1 ).

\section{Immediate effects of mechanical impact}

The acute mechanical overload during joint trauma can cause bone fracture, rupture of ligaments and menisci, lesions in the joint capsule and synovium, and compressive or shear damage to the articular cartilage. When cartilage is exposed to compressive and shear forces it can separate from the subchondral bone. Exposure to lower forces leads to immediate changes in cartilage cell viability due to necrosis, and cracks or fissures of the cartilage surface that can extend into the mid and deep zone, and leads to release of cartilage extracellular matrix molecules [9]. Compressive chondral injuries may not be evident at arthroscopy but are in some cases associated with subchondral bone marrow edema [10].

The synovial fluid is severely compromised in its lubricating function. This is the result of dilution due to intraarticular bleeding and plasma extravasation, leading to lower concentrations of hyaluronic acid and lubricin, the major joint lubricants. Neutrophil-derived enzymes degrade lubricin, and inflammatory mediators present in the posttraumatic synovial fluid suppress the synthesis of lubricin [11]. In patients with ACL injury, the decrease in lubricin is most marked in the days after injury and gradually approaches near-normal levels within 1 year [11].

The immediate collagen damage in cartilage is caused by mechanical rupture due to tensile failure [12].
Cartilage swelling occurs within hours after impact as the swelling pressure of the glycosaminoglycans (GAGs) is no longer restrained by an intact collagen network [13]. There is also rapid GAG loss that appears to result from the acute physical impact since it is not prevented by inhibitors of GAG-degrading enzymes [14].

Following these immediate changes is the acute posttraumatic phase, with activation of remaining viable cells in articular cartilage and other joint tissues that respond to the mechanical trauma with enhanced cell metabolism and the generation of oxygen radicals, matrix-degrading enzymes and inflammatory mediators. Mechanical injury also leads to suppression of collagen and GAG synthesis. A recovery from this suppression and an increase of new matrix synthesis can occur subsequently, but this is compromised by the presence of the inflammatory response [15].

\section{Hemarthrosis}

Rapidly developing intraarticular bleeding caused by rupture of blood vessels in the joint capsule, synovium, menisci or subchondral bone is observed in $>90 \%$ of patients with joint trauma that have surgically significant lesions such as osteochondral fracture, ligament or meniscus tears, but also occurs at lower frequency in patients without significant acute intraarticular pathology [16]. Hemarthrosis is an important factor in the pathogenesis of posttraumatic arthritis since even a single episode of intraarticular bleeding can lead to cartilage damage.

Experimental injection of autologous blood into normal joints causes loss of proteoglycans and inhibits proteoglycan synthesis [17]. In addition, exposure of articular cartilage in vitro to whole blood in the absence of other stimuli induces chondrocyte apoptosis. Neutrophils in acute hemarthrosis are activated and produce increased levels of reactive oxygen species, elastase and other lysosomal enzymes [18]. Extracellularly released elastase is a potent lysosomal enzyme that degrades proteoglycans. Mononuclear cells cause reversible suppression of GAG synthesis but this becomes irreversible in the presence of red blood cells. This irreversible inhibition is independent of the cytokines IL-1 and TNF 
but is in part dependent on oxygen radicals [19]. Hemoglobin degradation products such as deoxyhemoglobin, methemoglobin, and hemosiderin appear to mediate the blood-induced damage.

Hemarthrosis also leads to synovial hypertrophy and siderosis, due to phagocytosis of erythrocytes and hemoglobin by synovial cells. Synovitis develops only at later stages and may be triggered by mediators that result from cartilage damage, such as matrix degradation products or chondrocyte-derived cytokines [20]. There is thus strong evidence that intraarticular bleeding, even a single episode, leads to joint damage - and intraarticular bleeding should therefore be addressed in the treatment of posttraumatic arthritis. Additional bleeding at the time of surgery could in itself be deleterious to cartilage health and could potentially recapitulate and prolong the events initiated by the primary trauma.

\section{Arthrofibrosis}

Fibrogenesis resulting in clinically significant arthrofibrosis remains a problem due to the lack of efficient preventive and therapeutic strategies [21,22]. Presently, clinical management of arthrofibrosis emphasizes prevention strategies, including early passive range-of-motion exercises. Once fibrosis has developed, interventions consist of steroid injections, physical therapy and, ultimately, surgery for debridement. Arthrolysis surgery may be required more than once in some patients.

A key strategy for the prevention of arthrofibrosis is to delay the time to ACL reconstruction surgery for an acute ACL tear. This approach is supported by evidence that performing surgery within 4 weeks of ACL injury is a risk factor for postoperative development of arthrofibrosis [23]. The presence of preoperative swelling, effusion and hyperthermia correlated with development of arthrofibrosis [24]. Furthermore, if joint inflammation persisted after 4 weeks, the risk of arthrofibrosis remained elevated. These observations suggest it is inflammation, and not timing of the surgery, which predicts development of arthrofibrosis postoperatively. Attempts to reduce preoperative inflammation are therefore required to prevent this postsurgical complication.

\section{Posttraumatic cartilage cell death}

Cell death in cartilage has been identified as an important mechanism in the development of OA joint pathology [25]. Cell death has also become a focus of research on posttraumatic cartilage damage and has been studied in vitro, in open and closed impact animal models, as well as in human joints.

Cell death after traumatic cartilage impact occurs in two phases: an immediate phase due to cell necrosis, followed by a subsequent spreading of cell death mediated by apoptotic mechanisms beyond the initial area to the surrounding unimpacted regions [12,26-29], leading to expansion of the original lesion [9]. This progressive increase in apoptotic cells after injury offers a therapeutic window. Compressive loading of cartilage causes significant apoptotic cell death [26,30] that develops around matrix cracks, and there is a linear relationship between impact energy and cell death [31]. The cartilage superficial zone is most susceptible to cell death after mechanical injury [32]. Apoptosis has been demonstrated after mechanical injury in animal models and in human joint trauma as indicated by the activation of caspases, the enzymes that regulate and execute apoptosis [10]. A substantial increase in apoptotic cell death in cartilage was also observed after intraarticular fracture in humans [33,34].

The consequences of cell death are that it contributes to matrix degradation and depletes cartilage of the cells that are required to repair and maintain extracellular matrix. The percentage of apoptotic chondrocytes correlates with the level of GAG loss in the impacted tissues [35]. This suggests that cell death contributes to matrix degradation and deficient repair.

Observations on the short-term consequences of mechanical cartilage injury on apoptosis thus suggest that: in vivo chondrocyte apoptosis can be induced by a single impact load; the extent of apoptosis in vitro correlates with the intensity of the load applied and increases with time in culture; chondrocyte death can precede structural damage; caspase inhibitors reduce cell death, maintain functional cells and protect against extracellular matrix damage; and a therapeutic window exists where apoptosis can be inhibited.

\section{Inflammatory cytokines}

Cytokines in the IL-1 family are principal mediators of the acute posttraumatic inflammatory response [36,37]. Increased IL-1 expression has been documented after mechanical joint injury and correlates with the severity of cartilage damage [38]. IL-1 is overexpressed by chondrocytes, synoviocytes and infiltrating inflammatory cells. Furthermore, synovial fluid levels of the IL-1 receptor antagonist (IL-1Ra) decrease after ACL injury [39]. IL-1 induces mediators of joint pain, and it promotes cartilage matrix degradation by inducing expression of extracellular matrix-degrading enzymes and inhibiting extracellular matrix synthesis and the anabolic activity of growth factors $[40,41]$.

The levels of IL- 6 and TNF $\alpha$ in human synovial fluid also increase significantly after acute joint injury $[11,42]$. IL-6 with its soluble receptor potentiates the catabolic effects of TNF $\alpha$ in the degradation and loss of proteoglycans from cartilage [43]. Furthermore, mechanical injury potentiates proteoglycan catabolism induced by this combination of TNF $\alpha$ and IL- 6 with its soluble receptor [44]. This provides a potential 
mechanism linking the immediate and acute events following trauma.

\section{Extracellular matrix-degrading enzymes}

Release of extracellular matrix-degrading enzymes has been established as an important mechanism in posttraumatic cartilage damage. Fragments of extracellular matrix such as collagen or fibronectin fragments that are generated by these enzymes stimulate further production of pathogenetic mediators [45]. The specific enzymes, kinetics of release and cellular origin vary with the experimental model used. Studies with cartilage explants that are subjected to mechanical impact injury demonstrate that the remaining viable chondrocytes express increased levels of matrix metalloproteinase (MMP)-1, MMP-3, MMP-8, MMP-9, MMP-13 and ADAM-TS5 $[46,47]$. Analyses of synovial fluid samples taken from patients after an ACL or meniscal tear revealed increased MMP-3 levels that remained elevated for many years [48]. Joint fluid also showed an initial and persistent elevation of the neoepitope Col2CTx in the C-telopeptide of type II collagen, indicating digestion of mature, crosslinked collagen by a MMP. Fragments of cartilage oligomeric protein and aggrecan were also elevated [49-51].

Taken together, these studies suggest that extracellular matrix degradation rates are significantly altered within days of the injury and remain altered for years. The acute joint tissue response to the original mechanical insult thus seems to initiate an unbalanced degradative process that can significantly increase the risk of OA.

\section{Pharmacological treatment options}

There is a clear recognition of the risk to develop OA after joint trauma, and thus there is an obvious and urgent need to develop and implement strategies that prevent posttraumatic cartilage degradation. Here we focus on pharmacological interventions, but these need to be integrated with surgery and neuromuscular-biomechanical training. Research on pathogenetic mechanisms has identified major pathways and therapeutic targets. Pharmacological interventions need to inhibit the posttraumatic inflammatory responses, prevent cell death, prevent degradation and stimulate production of new cartilage extracellular matrix. The optimal therapy should address several or all of the pathogenesis pathways. Whether separate approaches are required to first interfere with early catabolic and inflammatory events and subsequently to promote anabolic responses, so that therapeutic approaches effectively stimulate proper cartilage repair at the appropriate time after trauma, needs to be determined. Goals of therapy are to provide immediate and long-term benefits, and it is possible that interventions during the first few months after injury can accomplish both. An important unanswered question is when and which therapies that have been developed as disease-modifying OA drugs [52] are indicated for patients with posttraumatic OA. A promising route of drug administration during the early phase after joint injury is intraarticular injection. This has the advantages of reaching high drug concentrations at the lesion site with low systemic drug exposure, and thus reduced risk for systemic adverse events.

Animal models used to test potential therapies include joint damage and OA-like pathology induced by creating joint instability through performing ligament transection and/or meniscectomy. These models are associated with chronic or repetitive impact loading, and lead to a rapid development of full thickness cartilage lesions within 3 to 8 weeks. Such models are the standard tools to evaluate disease-modifying OA drugs, and have been used to identify a large number of therapies that improve experimental lesions. A limitation of repetitive injury as a model of posttraumatic OA is that it disrupts endogenous repair responses. Single closed-impact injuries probably represent better models of human joint trauma. The closedimpact models are performed in larger animals $[53,54]$.

\section{Caspase inhibitors}

Evidence from in vitro and animal model studies suggests there is a time window after injury when cartilage cells can be rescued or protected from undergoing cell death, resulting in the maintenance of viable and functional cells and reducing cartilage structural damage [25]. This offers the opportunity of preventing chronic joint destruction, pain and disability by intraarticular administration of a pharmaceutical during the immediate time interval after joint injury. The key role that caspases play in initiating and executing apoptosis make them prime targets for apoptosis modulation. Antiapoptotic agents have been successfully explored in models of diseases affecting the central nervous system, liver and kidneys [55-57]. Specific to chondrocytes, a series of in vitro studies demonstrated that caspase inhibitors are effective in protecting against chondrocyte apoptosis, maintaining viable and functional cells [58]. Reduction of cartilage degeneration following intraarticular injection of caspase inhibitor has also been reported for a rabbit model of OA [59].

Caspases recognize substrates with a strict requirement for aspartic acid. Caspase inhibitors have been developed on dipeptide, tripeptide and tetrapeptide scaffolds that represent recognition sites in caspase substrates and a fluoromethylketone warhead [60]. The inhibitors differ in their specificity for individual caspases, in their ability to penetrate into the intracellular space and in whether they are reversible or irreversible inhibitors. In addition to the role of caspases in the regulation and execution of cell death, caspase 1 (also termed IL-converting enzyme) is responsible for converting the precursors of IL-1 family 
cytokines IL-1 $\beta$ and IL-18 to their active form. Pharmaceuticals that inhibit IL-converting enzyme/caspase-1 thus have potential to neutralize the pathogenic effects of IL-1 family cytokines [61].

Chemical caspase inhibitors are available that are specific for individual caspases or neutralize the activity of all caspases. Such pan-caspase inhibitors would be ideally suited to be effective as interventions for the acute posttraumatic inflammation and to limit cell and cartilage damage. The pan-caspase inhibitor z-VAD.fmk is a prototype compound that has been used extensively in vitro and in animal models for proof-of-concept studies. Inhibitors of specific caspases as well as pan-caspase inhibitors were tested in various models, and pan-caspase inhibitors appeared to be most potent in reducing chondrocyte apoptosis and GAG release [62,63]. A similar compound - a dipeptide-based, irreversible, cellpermeable and broad-spectrum caspase inhibitor [64] was evaluated in the treatment of liver disease and results from phase II clinical trials were published [65]. The drug showed no adverse effects and improved markers of liver damage in patients with chronic hepatitis $\mathrm{C}$ virus infection [65]. Proof-of-concept has thus been established for caspase inhibition as an effective therapy for diseases where tissue damage is related to cell death. Candidate drugs with established clinical safety are available for testing in posttraumatic arthritis.

\section{Cytokine inhibitors, anti-inflammatory cytokines}

IL-1 inhibition, mainly through the use of IL-1Ra, is therapeutically effective in animal models of OA $[66,67]$, and preliminary observations from a clinical trial in patients with OA suggest symptom-modifying activity [67]. In antigen-induced arthritis in rabbits, IL-1Ra also had a profound antifibrotic effect [68]. In this model, the synovial fibrosis was not only halted by administration of IL-1Ra but it was reversed [16]. Diacerhein, which interferes with the inflammatory and catabolic effects of IL-1, provided nearly complete protection in impact models [69]. TNF $\alpha$ inhibition by subcutaneous injection of a soluble TNF receptor fusion protein showed diseasemodifying activity in the anterior cruciate ligament transection model of posttraumatic arthritis in rats [70].

The anti-inflammatory cytokine IL-10 has a spectrum of chondroprotective activities in chondrocytes. It stimulates collagen type II and proteoglycan expression, inhibits MMP, proinflammatory cytokine or nitric oxide expression and protects against chondrocyte apoptosis (reviewed in [71]). IL-10 has also been therapeutically effective in an experimental animal model of early OA [72]. The chondroprotective potential of IL-4 has been demonstrated recently [73]. These observations suggest therapeutic potential of anti-inflammatory cytokines in posttraumatic cartilage damage [74].

\section{Growth factors}

Bone morphogenetic proteins (BMPs) are potent stimuli of mesenchymal cell differentiation and extracellular matrix formation. BMP-7, also termed osteogenic protein-1, has been studied extensively in vitro as well as in animal models, and results suggest that BMP-7 may be a candidate as a disease-modifying OA drug and also for posttraumatic arthritis. Unlike transforming growth factor beta and other BMPs, BMP-7 upregulates chondrocyte metabolism and protein synthesis without creating uncontrolled cell proliferation and formation of osteophytes. BMP-7 prevents chondrocyte catabolism induced by IL-1, fibronectin fragments or hyaluronan hexasaccharides. BMP-7 has synergistic anabolic effects with other growth factors such as insulin-like growth factor-1, which in addition to its anabolic effect acts as a cell survival factor (reviewed in [75]). Insulin-like growth factor-1 has chondroprotective activity in various animal models [76]. In acute chondral defect models in the dog [77] and goat [78], BMP-7 regenerated articular cartilage, increased repair tissue formation and improved integrative repair between new cartilage and the surrounding articular surface.

Fibroblast growth factors (FGFs) are important regulators of cartilage development and homeostasis [79]. FGF-2 can stimulate cartilage repair responses [80], but its potent mitogenic effects may lead to chondrocyte cluster formation and poor extracellular matrix due to a relatively low level of type II collagen [79]. In a rabbit anterior cruciate ligament transection model, however, sustained release formulations of FGF-2 reduced OA severity [81]. FGF-18 has anabolic effects on chondrocytes and chondroprogenitor cells, and stimulates cell proliferation and type II collagen production [82]. In a rat meniscal tear model of OA, intraarticular FGF-18 injections induced a remarkable formation of new cartilage and reduced the severity of the experimental lesions [83]. FGF-18 and BMP-7 are currently in clinical evaluation in patients with established OA.

\section{Inhibitors of extracellular matrix-degrading enzymes}

A large number of matrix-degrading enzymes - including MMPs, aggrecanases or cathepsins - are involved in cartilage matrix destruction in $\mathrm{OA}$, and inhibitors have been tested extensively in OA animal models. Several MMP inhibitors have been evaluated in clinical trials in patients with established OA, and failed either because of adverse events or lack of efficacy. The most common adverse event was termed musculoskeletal syndrome fibrotic lesions due to interference of the inhibitors with normal collagen turnover [52]. This may not represent a major risk if such drugs are administered intraarticularly or for short periods of time, for example, to limit the 
Table 2. Potential targets and drugs for pharmacological intervention in posttraumatic arthritis

\begin{tabular}{|c|c|c|}
\hline Target & Drugs & References \\
\hline Caspases & Small molecule inhibitors & {$[59,60,63,64$} \\
\hline Proinflammatory cytokines (TNFa, IL-1, IL-6) & Neutralizing antibodies, IL-converting enzyme, TACE inhibitors & {$[66-70]$} \\
\hline Cartilage repair & Growth factors (BMP-7, FGF-2, FGF-18, IGF-1) & {$[75-83]$} \\
\hline $\begin{array}{l}\text { Matrix-degrading enzymes (matrix metalloproteinases, } \\
\text { aggrecanases, cysteine-dependent cathepsins, } \\
\text { neutrophil-derived enzymes) }\end{array}$ & Small-molecule inhibitors, TIMP & [14] \\
\hline Oxygen radicals & SOD, SOD mimetics & [84-87] \\
\hline Lubricant deficiency & Lubricin, hyaluronan & {$[92,93]$} \\
\hline Anti-inflammatory cytokines & & {$[71-74]$} \\
\hline
\end{tabular}

SOD, superoxide dismutase; TACE, TNFa converting enzyme; TIMP, tissue inhibitors of metalloproteinases.

irreversible collagen degradation in the first few months after injury. Enzyme inhibitors have not been tested in single-impact animal models, but in cartilage explants a MMP inhibitor reduced GAG loss between 1 and 7 days post injury [14].

\section{Antioxidants}

Traumatic cartilage and joint injury is associated with increased production of reactive oxidant species and reduced antioxidant defenses, and this imbalance contributes to cell death and degradation of extracellular matrix [84]. Chondrocyte death induced by mechanical injury was reduced by antioxidants such as the superoxide dismutase mimic Mn(III)porphyrin [85], vitamin E and $N$ acetylcysteine [86]. Moreover, $N$-acetylcysteine treatment significantly improved proteoglycan content at the impact sites [87]. Brief exposure to free radical scavengers could thus significantly improve chondrocyte viability and protect against extracellular matrix damage following joint injury.

\section{Aminosugars}

Glucosamine is being used by a large number of OA patients but discussion of its efficacy and mechanism of action after oral administration continues. High concentrations of glucosamine and related aminosugars, however, have anabolic and anti-inflammatory effects on chondrocytes and other joint tissue cells [88]. Since such high concentrations in joints can presumably not be attained after oral administration, intraarticular injections may represent a feasible and effective approach. Among the various aminosugars that have been tested, $N$-acetylglucosamine has a superior spectrum of activities in vitro [89]. Intraarticular injection of $N$ acetylglucosamine was also effective in an animal model of OA [90].

\section{Joint lubricants}

Hyaluronan and lubricin are important lubricants of the cartilage surfaces. Lubricin concentrations in synovial fluid are reduced in patients with traumatic arthritis, due to enzymatic degradation and suppression of its synthesis by inflammatory cytokines $[11,91]$. In rats with meniscal tear-induced OA, intraarticular injections of recombinant lubricin resulted in disease-modifying, chondroprotective effects [92]. Similar to lubricin, hyaluronan is degraded in inflamed joints and there are numerous reports of chondroprotective activities in experimental models of OA [93]. Interestingly, both lubricin and hyaluronan have activities beyond lubrication that may be beneficial in the setting of posttraumatic arthritis.

\section{Conclusion}

$\mathrm{OA}$ is the most common form of joint disease affecting a patient population that is heterogeneous with regard to risk factors and stage of the disease. Disease-modifying OA therapies are presently not available. Approximately $50 \%$ of patients with traumatic joint injury develop OA and represent a subset of OA that is readily identified and accounts for approximately $12 \%$ of all OA cases. Unmet needs exist to address the acute posttraumatic inflammation and to prevent or delay the development of OA. Research on experimental models of posttraumatic OA and clinical research has led to the elucidation of pathogenesis pathways. The ideal therapy must be multi-varied and include positive effects on chondrocyte metabolism and stimulation of intrinsic repair while inhibiting catabolic pathways that lead to chondrocyte death and matrix loss. A series of molecular targets and drug candidates have been identified, and many of these drug candidates were effective in animal models of joint injury and OA (Table 2).

The current challenge and opportunity is in the translation of this information into effective therapies (Table 3). The major challenge is the long time interval, ranging from 5 to 15 years, between joint trauma and OA-like joint pathology in humans as detected on radiographs or magnetic resonance imaging. Since it is not feasible to conduct clinical trials of such duration, any therapy to be introduced into clinical use will thus 
Table 3. Posttraumatic osteoarthritis: needs, opportunities and challenges

Therapies needed for posttraumatic inflammation and osteoarthritis prevention

Readily identified population at high risk for osteoarthritis

Pathways and targets identified

Several clinical-stage therapeutic candidates

Therapeutic window immediately following injury

Long latency period until overt structural change

Clinical trials for osteoarthritis prevention depend on surrogate markers

depend on demonstrating efficacy on the basis of surrogate markers, such as biochemical markers that predict or correlate with the progression of cartilage and joint damage. Although candidate markers have been identified, they need further validation. A need also exists for therapies that address the acute joint inflammation and improve subjective symptoms such as pain, stiffness and joint dysfunction during the first 2 to 3 months after injury. Clinical trial design for such studies is facilitated by the availability of established endpoints for joint pain, function and inflammation. Based on the notion that the original lesion expands rapidly during this time, there is an opportunity to simultaneously address symptoms and limit lesion expansion.

We propose, as a near-term approach, interventions that should be tested as soon as possible after joint trauma with primary objectives to reduce pain and inflammation and with secondary objectives to improve biomarkers of joint destruction. Such therapies can be administered as injections into the affected joints, and have advantages of reduced risk for systemic adverse events and reaching high drug levels at the target tissues. Formulation technologies are available to extend intraarticular retention and thus limit the number of injections [94]. Several drug candidates have already been tested extensively in preclinical models, and some candidates have already been in human clinical trials for established OA or other indications.

\section{Abbreviations}

$\mathrm{ACL}$, anterior cruciate ligament; $\mathrm{BMP}$, bone morphogenetic protein; FGF, fibroblast growth factor; GAG, glycosaminoglycan; IL, interleukin; IL-1Ra, IL-1 receptor antagonist; MMP, matrix metalloproteinase; OA, osteoarthritis; TNF, tumor necrosis factor.

Acknowledgements

The present work was supported by NIH grants AR058954 and AG007996.

This article is part of a review series on New developments in osteoarthritis, edited by Martin Lotz and Stefan Lohmander. Other articles in the series can be found online at http://arthritis-research. com/series/osteoarthritis
Competing interest

The author declares that he has no competing interests.

Published: 28 June 2010

References

1. Buckwalter JA, Thomas TD: Joint injury, repair, and remodeling: roles in post-traumatic osteoarthritis. Clin Orthop Relat Res 2004, 423:7-16.

2. Brown TD, Johnston RC, Saltzman CL, Marsh JL, Buckwalter JA: Posttraumatic osteoarthritis: a first estimate of incidence, prevalence, and burden of disease. J Orthop Trauma 2006, 20:739-744.

3. Roos EM: Joint injury causes knee osteoarthritis in young adults. Curr Opin Rheumatol 2005, 17:195-200.

4. Gelber AC, Hochberg MC, Mead LA, Wang NY, Wigley FM, Klag MJ: Joint injury in young adults and risk for subsequent knee and hip osteoarthritis. Ann Intern Med 2000, 133:321-328.

5. Roos H, Adalberth T, Dahlberg L, Lohmander LS: Osteoarthritis of the knee after injury to the anterior cruciate ligament or meniscus: the influence of time and age. Osteoarthritis Cartilage 1995, 3:261-267.

6. Sherman MF, Warren RF, Marshall JL, Savatsky GJ: A clinical and radiographical analysis of 127 anterior cruciate insufficient knees. Clin Orthop Relat Res 1988, 227:229-237.

7. Johnson DL, Urban WP, Jr, Caborn DN, Vanarthos WJ, Carlson CS: Articular cartilage changes seen with magnetic resonance imaging-detected bone bruises associated with acute anterior cruciate ligament rupture. Am J Sports Med 1998, 26:409-414.

8. Nielsen $A B$, Yde J: Epidemiology of acute knee injuries: a prospective hospital investigation. J Trauma 1991, 31:1644-1648.

9. Otsuki S, Brinson DC, Creighton L, Kinoshita M, Sah RL, D'Lima D, Lotz M: The effect of glycosaminoglycan loss on chondrocyte viability: a study on porcine cartilage explants. Arthritis Rheum 2008, 58:1076-1085.

10. Colwell CW, Jr, D'Lima DD, Hoenecke HR, Fronek J, Pulido P, Morris BA, Chung C, Resnick D, Lotz M: In vivo changes after mechanical injury. Clin Orthop Relat Res 2001, 391(Suppl):S116-S123.

11. Elsaid KA, Fleming BC, Oksendahl HL, Machan JT, Fadale PD, Hulstyn MJ, Shalvoy R, Jay GD: Decreased lubricin concentrations and markers of joint inflammation in the synovial fluid of patients with anterior cruciate ligament injury. Arthritis Rheum 2008, 58:1707-1715.

12. Quinn TM, Grodzinsky AJ, Hunziker EB, Sandy JD: Effects of injurious compression on matrix turnover around individual cells in calf articular cartilage explants. J Orthop Res 1998, 16:490-499.

13. Maroudas Al: Balance between swelling pressure and collagen tension in normal and degenerate cartilage. Nature 1976, 260:808-809.

14. DiMicco MA, Patwari P, Siparsky PN, Kumar S, Pratta MA, Lark MW, Kim YJ, Grodzinsky AJ: Mechanisms and kinetics of glycosaminoglycan release following in vitro cartilage injury. Arthritis Rheum 2004, 50:840-848.

15. Patwari P, Kurz B, Sandy JD, Grodzinsky AJ: Mannosamine inhibits aggrecanase-mediated changes in the physical properties and biochemical composition of articular cartilage. Arch Biochem Biophys 2000 374:79-85

16. DeHaven KE: Diagnosis of acute knee injuries with hemarthrosis. Am J Sports Med 1980, 8:9-14.

17. Hooiveld M, Roosendaal G, Wenting M, van den Berg M, Bijlsma J, Lafeber F: Short-term exposure of cartilage to blood results in chondrocyte apoptosis. Am J Pathol 2003, 162:943-951.

18. Borsiczky B, Fodor B, Racz B, Gasz B, Jeges S, Jancso G, Roth E: Rapid leukocyte activation following intraarticular bleeding. J Orthop Res 2006 24:684-689.

19. Roosendaal G, TeKoppele JM, Vianen ME, van den Berg HM, Lafeber FP, Bijlsma JW: Blood-induced joint damage: a canine in vivo study. Arthritis Rheum 1999, 42:1033-1039.

20. Roosendaal G, Vianen ME, Wenting MJ, van Rinsum AC, van den Berg HM, Lafeber FP, Bijlsma JW: Iron deposits and catabolic properties of synovial tissue from patients with haemophilia. J Bone Joint Surg Br 1998, 80:540-545.

21. Cosgarea AJ, DeHaven KE, Lovelock JE: The surgical treatment of arthrofibrosis of the knee. Am J Sports Med 1994, 22:184-191.

22. Shelbourne KD, Wilckens JH, Mollabashy A, DeCarlo M: Arthrofibrosis in acute anterior cruciate ligament reconstruction. The effect of timing of reconstruction and rehabilitation. Am J Sports Med 1991, 19:332-336.

23. Passler JM, Schippinger G, Schweighofer F, Fellinger M, Seibert FJ: Complications in 283 cruciate ligament replacement operations with free 
patellar tendon transplantation. Modification by surgical technique and surgery timing. Unfallchirurgie 1995, 21:240-246.

24. Mayr HO, Weig TG, Plitz W: Arthrofibrosis following ACL reconstructionreasons and outcome. Arch Orthop Trauma Surg 2004, 124:518-522.

25. Kuhn K, D'Lima DD, Hashimoto S, Lotz M: Cell death in cartilage. Osteoarthritis Cartilage 2004, 12:1-16.

26. D'Lima D, Hashimoto S, Chen P, Colwell C, Lotz M: Human chondrocyte apoptosis in response to mechanical injury. Osteoarthritis Cartilage 2001, 9:712-719.

27. Duda GN, Eilers M, Loh L, Hoffman JE, Kaab M, Schaser K: Chondrocyte death precedes structural damage in blunt impact trauma. Clin Orthop Relat Res 2001, 393:302-309

28. Levin A, Burton-Wurster N, Chen CT, Lust G: Intercellular signaling as a cause of cell death in cyclically impacted cartilage explants. Osteoarthritis Cartilage 2001, 9:702-711

29. Morel V, Quinn TM: Short-term changes in cell and matrix damage following mechanical injury of articular cartilage explants and modelling of microphysical mediators. Biorheology 2004, 41:509-519.

30. Chen CT, Burton-Wurster N, Borden C, Hueffer K, Bloom SE, Lust G: Chondrocyte necrosis and apoptosis in impact damaged articular cartilage. J Orthop Res 2001, 19:703-711.

31. Jeffrey JE, Gregory DW, Aspden RM: Matrix damage and chondrocyte viability following a single impact load on articular cartilage. Arch Biochem Biophys 1995, 322:87-96.

32. Torzilli PA, Grigiene R, Borrelli J, Jr, Helfet DL: Effect of impact load on articular cartilage: cell metabolism and viability, and matrix water content. J Biomech Eng 1999, 121:433-441.

33. Kim HT, Lo MY, Pillarisetty R: Chondrocyte apoptosis following intraarticular fracture in humans. Osteoarthritis Cartilage 2002, 10:747-749.

34. Murray MM, Zurakowski D, Vrahas MS: The death of articular chondrocytes after intra-articular fracture in humans. J Trauma 2004, 56:128-131.

35. D'Lima DD, Hashimoto S, Chen PC, Colwell CW, Jr, Lotz MK: Impact of mechanical trauma on matrix and cells. Clin Orthop Relat Res 2001, 391(Suppl):S90-S99.

36. Guilak F, Fermor B, Keefe FJ, Kraus VB, Olson SA, Pisetsky DS, Setton LA Weinberg JB: The role of biomechanics and inflammation in cartilage injury and repair. Clin Orthop Relat Res 2004, 423:17-26.

37. Furman $\mathrm{BD}$, Olson $\mathrm{SA}$, Guilak F: The development of posttraumatic arthritis after articular fracture. J Orthop Trauma 2006, 20:719-725

38. Marks PH, Donaldson ML: Inflammatory cytokine profiles associated with chondral damage in the anterior cruciate ligament-deficient knee. Arthroscopy 2005, 21:1342-1347

39. Cameron ML, Fu FH, Paessler HH, Schneider M, Evans CH: Synovial fluid cytokine concentrations as possible prognostic indicators in the ACLdeficient knee. Knee Surg Sports Traumatol Arthrosc 1994, 2:38-44

40. Chandrasekhar S, Harvey AK, Hrubey PS: Intra-articular administration of interleukin-1 causes prolonged suppression of cartilage proteoglycan synthesis in rats. Matrix 1992, 12:1-10.

41. van den Berg WB, Joosten LA, van de Loo FA: TNF alpha and IL-1 beta are separate targets in chronic arthritis. Clin Exp Rheumatol 1999, 17(6 Suppl 18):S105-S114

42. Irie $\mathrm{K}$, Uchiyama $\mathrm{E}$, Iwaso $\mathrm{H}$ : Intraarticular inflammatory cytokines in acute anterior cruciate ligament injured knee. Knee 2003, 10:93-96

43. Flannery CR, Little CB, Hughes CE, Curtis CL, Caterson B, Jones SA: IL-6 and its soluble receptor augment aggrecanase-mediated proteoglycan catabolism in articular cartilage. Matrix Biol 2000, 19:549-553.

44. Sui Y, Lee JH, DiMicco MA, Vanderploeg EJ, Blake SM, Hung HH, Plaas AH, James IE, Song XY, Lark MW, Grodzinsky AJ: Mechanical injury potentiates proteoglycan catabolism induced by interleukin- 6 with soluble interleukin- 6 receptor and tumor necrosis factor alpha in immature bovine and adult human articular cartilage. Arthritis Rheum 2009, 60:2985-2996

45. Guo D, Ding L, Homandberg GA: Telopeptides of type II collagen upregulate proteinases and damage cartilage but are less effective than highly active fibronectin fragments. Inflamm Res 2009, 58:161-169.

46. Patwari P, Cook MN, DiMicco MA, Blake SM, James IE, Kumar S, Cole AA, Lark MW, Grodzinsky AJ: Proteoglycan degradation after injurious compression of bovine and human articular cartilage in vitro: interaction with exogenous cytokines. Arthritis Rheum 2003, 48:1292-1301.

47. Lee JH, Fitzgerald JB, Dimicco MA, Grodzinsky AJ: Mechanical injury of cartilage explants causes specific time-dependent changes in chondrocyte gene expression. Arthritis Rheum 2005, 52:2386-2395

48. Lohmander LS, Hoerrner LA, Dahlberg L, Roos H, Bjornsson S, Lark MW: Stromelysin, tissue inhibitor of metalloproteinases and proteoglycan fragments in human knee joint fluid after injury. J Rheumatol 1993, 20:1362-1368

49. Lohmander LS, Saxne T, Heinegard DK: Release of cartilage oligomeric matrix protein (COMP) into joint fluid after knee injury and in osteoarthritis. Ann Rheum Dis 1994, 53:8-13.

50. Lohmander LS, Ionescu M, Jugessur H, Poole AR: Changes in joint cartilage aggrecan after knee injury and in osteoarthritis. Arthritis Rheum 1999, 42:534-544.

51. Tchetverikov I, Lohmander LS, Verzijl N, Huizinga TW, TeKoppele JM, Hanemaaijer R, DeGroot J: MMP protein and activity levels in synovial fluid from patients with joint injury, inflammatory arthritis, and osteoarthritis. Ann Rheum Dis 2005, 64:694-698.

52. Hellio Le Graverand-Gastineau MP: OA clinical trials: current targets and trials for OA. Choosing molecular targets: what have we learned and where we are headed? Osteoarthritis Cartilage 2009, 17:1393-1401.

53. Thompson RC, Jr, Oegema TR, Jr, Lewis JL, Wallace L: Osteoarthrotic changes after acute transarticular load. An animal model. J Bone Joint Surg Am 1991, 73:990-1001

54. Newberry WN, Garcia JJ, Mackenzie CD, Decamp CE, Haut RC: Analysis of acute mechanical insult in an animal model of post-traumatic osteoarthrosis. J Biomech Eng 1998, 120:704-709.

55. Hara H, Friedlander RM, Gagliardini V, Ayata C, Fink K, Huang Z, ShimizuSasamata M, Yuan J, Moskowitz MA: Inhibition of interleukin $1 \beta$ converting enzyme family proteases reduces ischemic and excitotoxic neuronal damage. Proc Natl Acad SciU S A 1997, 94:2007-2012

56. Canbay A, Feldstein A, Baskin-Bey E, Bronk SF, Gores GJ: The caspase inhibitor IDN-6556 attenuates hepatic injury and fibrosis in the bile duct ligated mouse. J Pharmacol Exp Ther 2004, 308:1191-1196.

57. Daemen MA, van't Veer C, Denecker G, Heemskerk VH, Wolfs TG, Clauss M, Vandenabeele P, Buurman WA: Inhibition of apoptosis induced by ischemiareperfusion prevents inflammation. J Clin Invest 1999, 104:541-549.

58. Nuttall ME, Nadeau DP, Fisher PW, Wang F, Keller PM, DeWolf WE, Jr, Goldring MB, Badger AM, Lee D, Levy MA, Gowen M, Lark MW: Inhibition of caspase3-like activity prevents apoptosis while retaining functionality of human chondrocytes in vitro. J Orthop Res 2000, 18:356-363.

59. D'Lima D, Hermida J, Hashimoto S, Colwell C, Lotz M: Caspase inhibitors reduce severity of cartilage lesions in experimental osteoarthritis. Arthritis Rheum 2006, 54:1814-1821.

60. Linton SD: Caspase inhibitors: a pharmaceutical industry perspective. Curr Top Med Chem 2005, 5:1697-1717.

61. Cornelis S, Kersse K, Festjens N, Lamkanfi M, Vandenabeele P: Inflammatory caspases: targets for novel therapies. Curr Pharm Des 2007, 13:367-385.

62. D'Lima DD, Hashimoto S, Chen PC, Lotz MK, Colwell CW, Jr: Prevention of chondrocyte apoptosis. J Bone Joint Surg Am 2001, 83-A(Suppl 2, Pt 1):25-26.

63. Huser CA, Peacock M, Davies ME: Inhibition of caspase-9 reduces chondrocyte apoptosis and proteoglycan loss following mechanical trauma. Osteoarthritis Cartilage 2006, 14:1002-1010.

64. Linton SD, Aja T, Armstrong RA, Bai X, Chen LS, Chen N, Ching B, Contreras P, Diaz JL, Fisher CD, Fritz LC, Gladstone P, Groess I T, Gu X, Herrmann J, Hirakawa BP, Hoglen NC, Jahangiri KG, Kalish VJ, Karanewsky DS, Kodandapani L, Krebs J, McQuiston J, Meduna SP, Nalley K, Robinson ED, Sayers RO, Sebring K, Spada AP, Ternansky RJ, Tomaselli KJ, Ullman BR, Valentino KL, Weeks S, Winn D, Wu J C, Yeo P, Zhang CZ: First-in-class pan caspase inhibitor developed for the treatment of liver disease. J Med Chem 2005, 48:6779-6782.

65. Pockros PJ, Schiff ER, Shiffman ML, McHutchison JG, Gish RG, Afdhal NH, Makhviladze M, Huyghe M, Hecht D, Oltersdorf T, Shapiro DA: Oral IDN-6556, an antiapoptotic caspase inhibitor, may lower aminotransferase activity in patients with chronic hepatitis C. Hepatology 2007, 46:324-329.

66. Pelletier JP, Caron JP, Evans C, Robbins PD, Georgescu HI, Jovanovic D, Fernandes JC, Martel-Pelletier J: In vivo suppression of early experimental osteoarthritis by interleukin-1 receptor antagonist using gene therapy. Arthritis Rheum 1997, 40:1012-1019.

67. Chevalier X, Giraudeau B, Conrozier T, Marliere J, Kiefer P, Goupille P: Safety study of intraarticular injection of interleukin-1 receptor antagonist in patients with painful knee osteoarthritis: a multicenter study. J Rheumatol 2005, 32:1317-1323.

68. Lewthwaite J, Blake S, Thompson RC, Hardingham TE, Henderson B: 
Antifibrotic action of interleukin-1 receptor antagonist in lapine monoarticular arthritis. Ann Rheum Dis 1995, 54:591-596.

69. Mazieres B, Berdah L, Thiechart M, Viguier G: Diacetylrhein on a postcontusion model of experimental osteoarthritis in the rabbit. Rev Rhum Ed Fr 1993, 60(6 Pt 2):77S-81S

70. Elsaid KA, Machan JT, Waller K, Fleming BC, Jay GD: The impact of anterior cruciate ligament injury on lubricin metabolism and the effect of inhibiting tumor necrosis factor alpha on chondroprotection in an animal model. Arthritis Rheum 2009, 60:2997-3006.

71. Schulze-Tanzil G, Zreiqat H, Sabat R, Kohl B, Halder A, Muller RD, John T: Interleukin-10 and articular cartilage: experimental therapeutical approaches in cartilage disorders. Curr Gene Ther 2009 [Epub ahead of print].

72. Zhang $X$, Mao Z, Yu C: Suppression of early experimental osteoarthritis by gene transfer of interleukin-1 receptor antagonist and interleukin-10. J Orthop Res 2004, 22:742-750.

73. Rachakonda PS, Rai MF, Manning K, Schmidt MF: Expression of canine interleukin- 4 in canine chondrocytes inhibits inflammatory cascade through STAT6. Cytokine 2008, 44:179-184.

74. Gelse K, von der Mark K, Aigner T, Park J, Schneider H: Articular cartilage repair by gene therapy using growth factor-producing mesenchymal cells. Arthritis Rheum 2003, 48:430-441.

75. Chubinskaya S, Hurtig M, Rueger DC: OP-1/BMP-7 in cartilage repair. Int Orthop 2007, 31:773-781.

76. Fortier LA, Mohammed HO, Lust G, Nixon AJ: Insulin-like growth factor-I enhances cell-based repair of articular cartilage. J Bone Joint Surg Br 2002, 84:276-288.

77. Cook SD, Patron LP, Salkeld SL, Rueger DC: Repair of articular cartilage defects with osteogenic protein-1 (BMP-7) in dogs. J Bone Joint Surg Am 2003, 85-A(Suppl 3):116-123.

78. Louwerse RT, Heyligers IC, Klein-Nulend J, Sugihara S, van Kampen GP, Semeins CM, Goei SW, de Koning MH, Wuisman PI, Burger EH: Use of recombinant human osteogenic protein-1 for the repair of subchondral defects in articular cartilage in goats. J Biomed Mater Res 2000, 49:506-516.

79. Ellman MB, An HS, Muddasani P, Im HJ: Biological impact of the fibroblast growth factor family on articular cartilage and intervertebral disc homeostasis. Gene 2008, 420:82-89.

80. Henson FM, Bowe EA, Davies ME: Promotion of the intrinsic damage-repair response in articular cartilage by fibroblastic growth factor-2. Osteoarthritis Cartilage 2005, 13:537-544

81. Inoue A, Takahashi KA, Arai Y, Tonomura H, Sakao K, Saito M, Fujioka M, Fujiwara H, Tabata Y, Kubo T: The therapeutic effects of basic fibroblast growth factor contained in gelatin hydrogel microspheres on experimental osteoarthritis in the rabbit knee. Arthritis Rheum 2006 , 54:264-270.

82. Ellsworth JL, Berry J, Bukowski T, Claus J, Feldhaus A, Holderman S, Holdren MS, Lum KD, Moore EE, Raymond F, Ren H, Shea P, Sprecher C, Storey H, Thompson DL, Waggie K, Yao L, Fernandes RJ, Eyre DR, Hughes SD: Fibroblast growth factor-18 is a trophic factor for mature chondrocytes and their progenitors. Osteoarthritis Cartilage 2002, 10:308-320.
83. Moore EE, Bendele AM, Thompson DL, Littau A, Waggie KS, Reardon B, Ellsworth JL: Fibroblast growth factor-18 stimulates chondrogenesis and cartilage repair in a rat model of injury-induced osteoarthritis. Osteoarthritis Cartilage 2005, 13:623-631.

84. Martin JA, Brown T, Heiner A, Buckwalter JA: Post-traumatic osteoarthritis: the role of accelerated chondrocyte senescence. Biorheology 2004, 41:479-491.

85. Kurz B, Lemke A, Kehn M, Domm C, Patwari P, Frank EH, Grodzinsky AJ Schunke M: Influence of tissue maturation and antioxidants on the apoptotic response of articular cartilage after injurious compression. Arthritis Rheum 2004, 50:123-130.

86. Beecher BR, Martin JA, Pedersen DR, Heiner AD, Buckwalter JA: Antioxidants block cyclic loading induced chondrocyte death. Iowa Orthop J 2007, 27:1-8.

87. Martin JA, McCabe D, Walter M, Buckwalter JA, McKinley TO: $N$-acetylcysteine inhibits post-impact chondrocyte death in osteochondral explants. J Bone Joint Surg Am 2009, 91:1890-1897.

88. Herrero-Beaumont G, Rovati LC, Castaneda S, Alvarez-Soria MA, Largo R: The reverse glucosamine sulfate pathway: application in knee osteoarthritis. Expert Opin Pharmacother 2007, 8:215-225.

89. Shikhman AR, Kuhn K, Alaaeddine N, Lotz M: $N$-acetylglucosamine prevents IL-1 $\beta$-mediated activation of human chondrocytes. J Immunol 2001, 166:5155-5160.

90. Shikhman AR, Amiel D, D'Lima D, Hwang SB, Hu C, Xu A, Hashimoto S, Kobayashi K, Sasho T, Lotz MK: Chondroprotective activity of $\mathrm{N}$-acetylglucosamine in rabbits with experimental osteoarthritis. Ann Rheum Dis 2005, 64:89-94.

91. Jones AR, Chen S, Chai DH, Stevens AL, Gleghorn JP, Bonassar LJ, Grodzinsky AJ, Flannery CR: Modulation of lubricin biosynthesis and tissue surface properties following cartilage mechanical injury. Arthritis Rheum 2009, 60:133-142.

92. Flannery CR, Zollner R, Corcoran C, Jones AR, Root A, Rivera-Bermudez MA, Blanchet T, Gleghorn JP, Bonassar LJ, Bendele AM, Morris EA, Glasson SS: Prevention of cartilage degeneration in a rat model of osteoarthritis by intraarticular treatment with recombinant lubricin. Arthritis Rheum 2009 60:840-847.

93. Axe MJ, Shields $\mathrm{CL}$, Jr: Potential applications of hyaluronans in orthopaedics: degenerative joint disease, surgical recovery, trauma and sports injuries. Sports Med 2005, 35:853-864.

94. Larsen C, Ostergaard J, Larsen SW, Jensen H, Jacobsen S, Lindegaard C, Andersen PH: Intra-articular depot formulation principles: role in the management of postoperative pain and arthritic disorders. J Pharm Sci 2008, 97:4622-4654.

doi:10.1186/ar3046

Cite this article as: Lotz MK: Posttraumatic osteoarthritis: pathogenesis and pharmacological treatment options. Arthritis Research \& Therapy 2010, 12:211. 